\title{
Activation of conventional protein kinase C (PKC) is critical in the generation of human neutrophil extracellular traps
}

\author{
Robert D Gray*, Christopher D Lucas, Annie MacKellar, Feng Li, Katia Hiersemenzel, Chris Haslett, \\ Donald J Davidson ${ }^{\dagger}$ and Adriano G Rossi ${ }^{\dagger}$
}

\begin{abstract}
Background: Activation of NADPH oxidase is required for neutrophil extracellular trap (NET) formation. Protein kinase $C$ (PKC) is an upstream mediator of NADPH oxidase activation and thus likely to have a role in NET formation.

Methods: Pharmacological inhibitors were used to block PKC activity in neutrophils harvested from healthy donor blood.

Results: Pan PKC inhibition with Ro-31-8220 ( $p<0.001$ ), conventional PKC inhibition with Go $6976(p<0.001)$ and specific PKC 3 inhibition with LY333531 ( $p<0.01)$ blocked NET formation in response to PMA. Inhibition of novel and atypical PKC had no effect. LY333531 blocked NET induction by the diacylglycerol analogue OAG (conventional PKC activator) $(p<0.001)$.
\end{abstract}

Conclusions: Conventional PKCs have a prominent role in NET formation. Furthermore PKC $\beta$ is the major isoform implicated in NET formation.

\section{Introduction}

Neutrophil granulocytes are key cells of the innate immune system with a primary function of killing invading microorganisms such as bacteria, fungi and parasites to prevent pathogenic spread and invasion [1,2]. Once identified, neutrophils phagocytose and destroy microbes inside the phagolysosome by localised disgorgement of granule contents and the generation of reactive oxygen species (ROS) [3]. Engulfment of the microorganism allows killing to take place in a confined area within the cell and not in the extracellular space. Neutrophils may also liberate granule contents and ROS into the surrounding extracellular space to destroy nearby foreign pathogens. Dysregulation of these processes may cause histotoxic damage surrounding host cells. More recently a further extracellular killing mechanism available to neutrophils has been described known as neutrophil extracellular

\footnotetext{
*Correspondence: r.d.gray@ed.ac.uk

tEqual contributors

MRC Centre for Inflammation Research, The Queen's Medical Research Institute, University of Edinburgh Medical School, 47 Little France Crescent, Edinburgh, Scotland, UK
}

\section{Biomed Central}

(c) 2013 Gray et al.; licensee BioMed Central Ltd. This is an Open Access article distributed under the terms of the Creative Commons Attribution License (http://creativecommons.org/licenses/by/2.0), which permits unrestricted use, distribution, and reproduction in any medium, provided the original work is properly cited. trap (NEI) formation [3,4]. NETs are formed by the mixing of cytoplasmic contents with nuclear histones and DNA to form a network which is propelled to the exterior of the cell. Microbes are caught in this mesh and killed by the neutrophil proteins and histones contained in the NETs. This process of NET formation leads to a form of cell death, NETosis, that has been characterised as being different from either apoptosis or necrosis [5].

NET formation is known to be stimulated by specific cytokines (e.g., interleukin 8 (IL-8)), bacterial products (e.g., lipopolysaccharide (LPS)) and importantly by clinically relevant pathogens such as Shigella flexneri, Staphylococcus aureus, Salmonella thyphimurium, Streptococcus pneumoniae and the fungus Candida albicans [6]. Stimulation and activation of neutrophils with the diacylglycerol (DAG) mimetic phorbol 12-myristate 13-acetate (PMA) also results in the production of NETs and has given important clues as to the possible mechanism involved in the formation of such structures. It is clear that NET formation following PMA stimulation is dependent on ROS production (via the NADPH oxidase system) and this is 
likely to follow the activation of protein kinase $\mathrm{C}$ (PKC) as well as other pathways such as raf-MEK-ERK [7].

The PKC isozyme family is comprised of conventional, novel and atypical isoforms [8]. There are at least four conventional isozymes: PKC $\alpha, \mathrm{PKC} \beta \mathrm{I}, \mathrm{PKC} \beta \mathrm{II}$ and $\mathrm{PKC} \gamma$. The novel isozyme group has four subtypes: $\mathrm{PKC} \delta, \mathrm{PKC} \varepsilon$, $\mathrm{PKC} \eta$ and $\mathrm{PKC} \theta$. The third group, atypical isozymes, consists of PKC $\zeta$ and PKCi [9]. PMA stimulates conventional $(\alpha, \beta I, \beta I I, \gamma)$ and novel $(\delta, \varepsilon, \eta, \theta)$ PKC by mimicking the activating ligand DAG [8]. PKC isoforms of all classifications have been reported in neutrophils from healthy donors [10]. Given that PMA activation triggers NET formation, we hypothesised that specific isoform(s) of PKC are a key modulator of the NET formation pathway. To address this hypothesis we evaluated a panel of PKC inhibitors on NET formation.

\section{Material and methods Reagents}

Dihydrorhodamine (DHR), dimethyl sulfoxide (DMSO), diphenyliodonium (DPI), Phorbol 12-myristate 13-acetate (PMA), Ro-31-8220, PKCל pseudosubstrate myristoyl trifluoroacetate (PKC) inhibitor) and SYTOX green were purchased from Sigma-Aldrich (Dorset, UK); Rottlerin, Gö 6976 and LY333531 were from Calbiochem (Merck) (Darmstadt, Germany).

\section{Isolation of human neutrophils}

Peripheral blood neutrophils were isolated from healthy human volunteers according to Lothian Research Ethics Committee approvals \#08/S1103/38 via dextran sedimentation and Percoll ${ }^{\mathrm{Ts}}$ discontinuous gradients as described [11,12]. Informed written consent was obtained from all subjects. Purity of the neutrophils was assessed by examination of cytocentrifuge preparations and was greater than $95 \%$.

\section{Assessment of NET formation}

Neutrophils $\left(5 \times 10^{4}\right.$ cells/well) in HBSS containing $\mathrm{Ca}^{2+}$, $\mathrm{Mg}^{2+}$ and Hepes $(20 \mathrm{mM})$ were aliquoted $(180 \mu \mathrm{l})$ into 96 well plates and left to settle for $30 \mathrm{~min}$ at $37^{\circ} \mathrm{C}$. The inhibitors Ro-31-8220, DPI, rottlerin, PKC $\zeta$ inhibitor, Gö 6976 and PKC $\beta$ inhibitor were added at appropriate concentrations to wells in duplicates and incubated for $30 \mathrm{~min}$ before adding PMA. The final volume in each well was $200 \mu$ l. Plates were incubated for $4 \mathrm{~h}$ and then SYTOX green $(6 \mu \mathrm{M}$ final concentration), a cell-impermeable nucleic acid stain, with an excitation/emission maxima of 504/523 $\mathrm{nm}$ to give a green fluorescent light, was added and NET formation was observed by measuring mean fluorescence in 96 well plates. In some experiments 1-oleoyl-2-acetyl-snglycerol (OAG) was used to stimulate cells in place of PMA. Results were evaluated by measuring the mean fluorescence in 96 well plates after the subtraction of background fluorescence. Cells were also visualised by fluorescent microscopy carried out on a Zeiss Axiovert S100 fluorescent microscope (Carl Zeiss, Germany) and an Evos fl inverted microscope (AMG, Bothwell, WA).

\section{Statistical analysis}

Data were assessed by one way ANOVA followed by a post-hoc Dunnett's test. The data were expressed as mean \pm standard error of the mean (SEM), and values of $\mathrm{p}<0.05$ were considered statistically significant. All statistics were performed using GraphPad Prism 5 software (GraphPad, CA, USA).

\section{Results \\ PMA induced NET formation}

Incubation of human neutrophils with PMA induced dramatic changes in morphology at $4 \mathrm{~h}$ after stimulation, resulting in NETs that stained positive with SYTOX green which is impermeable to cells with an intact membrane. The abundance of NETs was almost maximal at 10 nM PMA above which the magnitude of NET formation plateaued (Figure 1A-N). Cells stimulated with PMA demonstrated typical morphology of diffuse and spread NETs (Figure 1M). Measuring the level of total fluorescence with SYTOX green allowed the assessment of total extracellular DNA and thus NET formation (Figure $1 \mathrm{~N}$ ). NET formation determined by microscopy and cell counting (i.e., by expressing the number of areas of extracellular DNA as a percentage of total cell count [14]) strongly correlated with the measurement of NET abundance based on total fluorescence $\left(r^{2}=0.98\right)$, data not shown. Therefore total fluorescence was utilised as a reliable screening assay in further experiments to allow a range of inhibitors to be compared, before confirmation with gold-standard microscopic validation. This test was reproducible with an average inter-assay coefficient of variation of $14.3 \%$. As almost maximal NET formation was gained with $10 \mathrm{nM}$ PMA (Figure 1B), this concentration was selected for all further experiments.

\section{NET formation is PKC and NADPH oxidase dependent}

In order to determine whether NET formation was dependent on the activation of PKC and NADPH oxidase, cells were preincubated with increasing concentrations of the specific but isozyme non-selective PKC inhibitor, Ro31-8220 or the NADPH inhibitor diphenyloidonium (DPI) for $30 \mathrm{~min}$ and then treated with $10 \mathrm{nM}$ PMA. Both Ro31-8220 and DPI, completely inhibited PMA induced NET formation (Figure 2A and 2B) measured by SYTOX green fluorescence and confirmed by microscopy. These data confirm the key role of NADPH oxidase and 


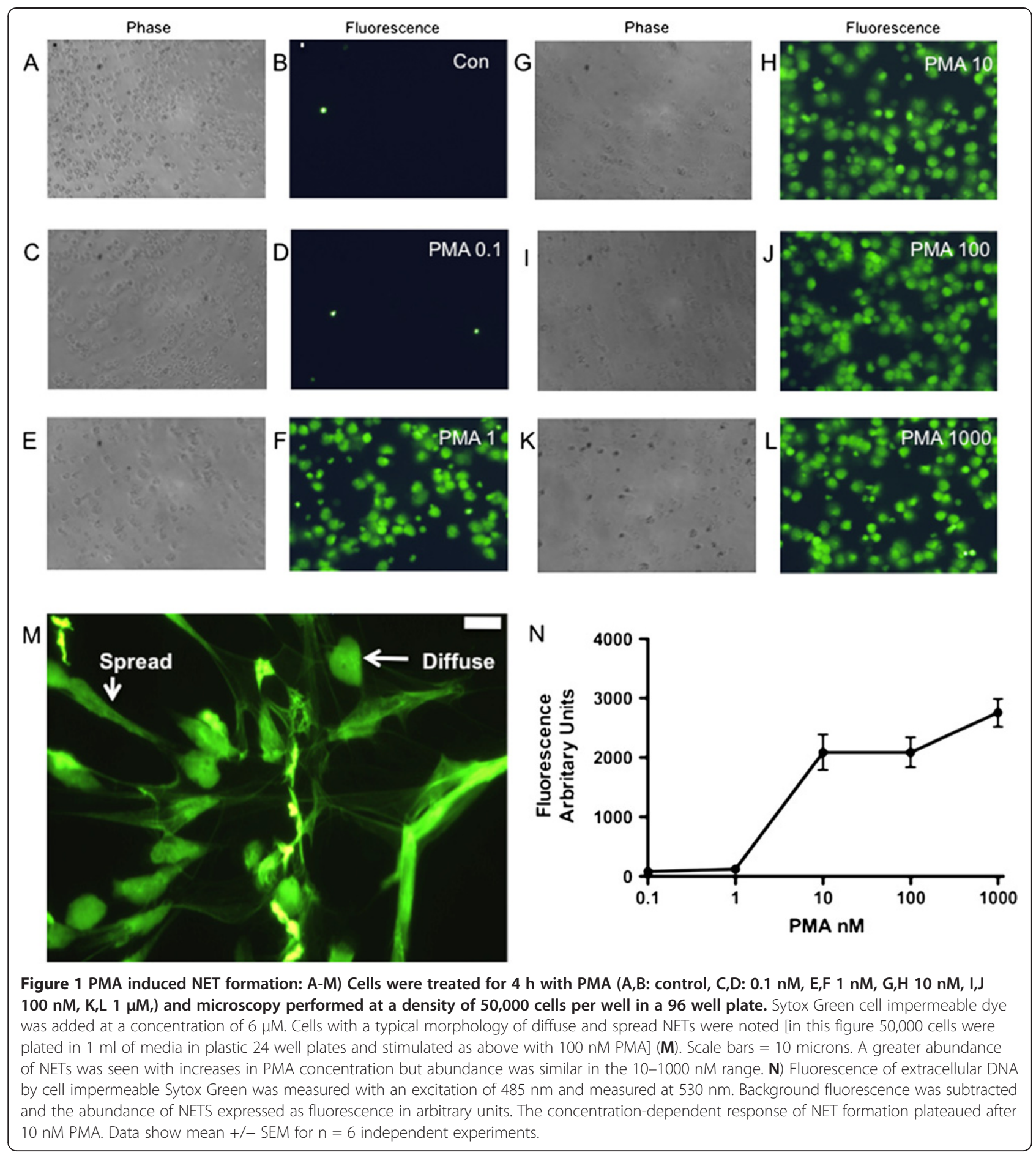

demonstrate that the NET-forming activity of PMA is critically dependent upon PKC pathways upstream of NADPH oxidase.

\section{Specific PKC isoforms regulated NET formation}

Ro-31-8220 is an inhibitor of multiple PKC isoforms, therefore in order to investigate $\mathrm{PKC}$ isoform specificity,
PKC isoform classes were targeted with specific inhibitors; Gö 6976 (Conventional), rottlerin (Novel), PKCל psuedosubstrate (Atypical) (Figure 3A, B, C). Figure 3A demonstrates that Gö 6976 significantly inhibited NET formation at $100 \mathrm{nM}(\mathrm{p}<0.05)$ and $1 \mu \mathrm{M}(\mathrm{p}<0.001)$. In contrast, Rottlerin and $\mathrm{PKC} \zeta$ psuedosubstrate had no significant effect on NET formation (Figure $3 \mathrm{~B}$ and C). These 


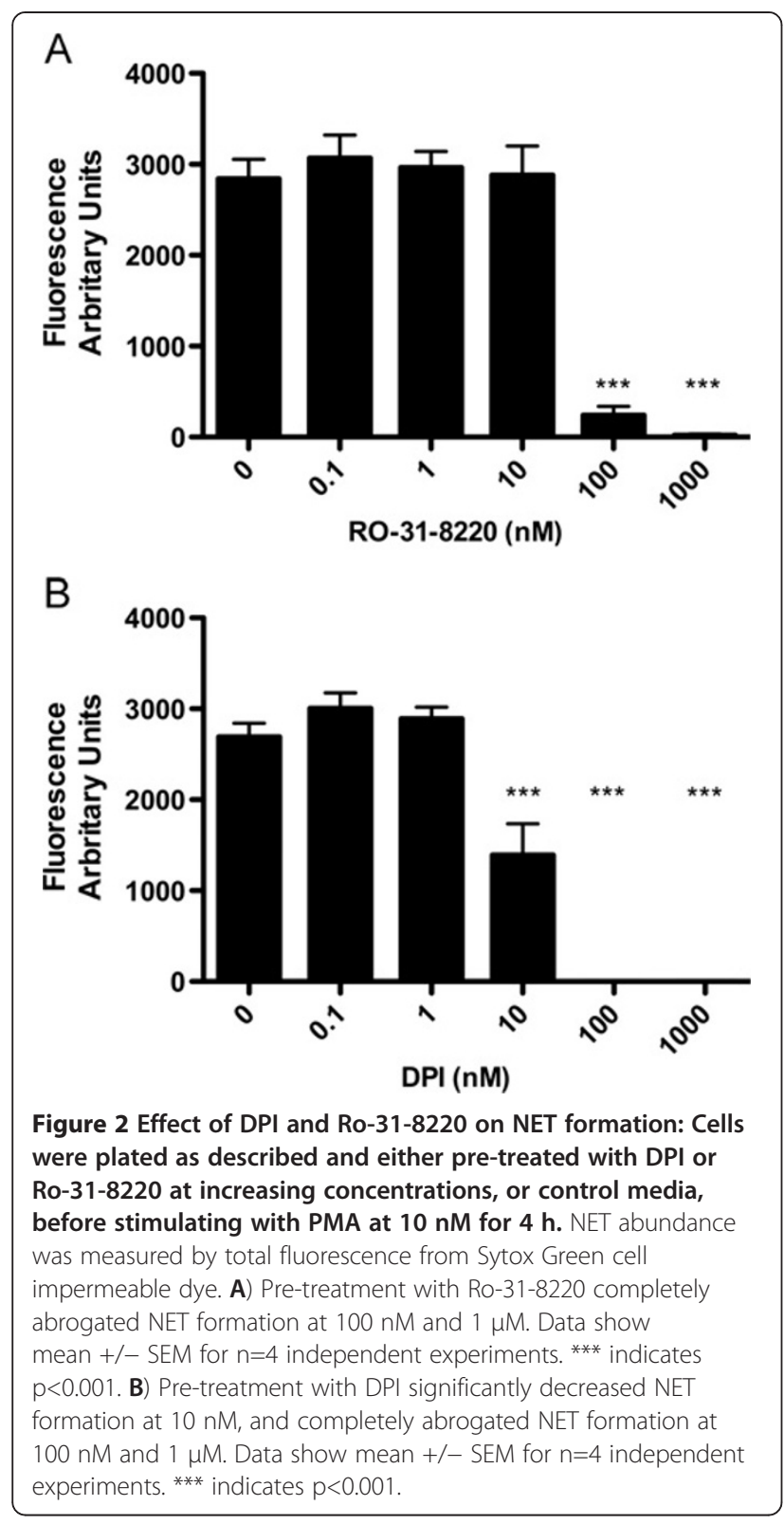

data were confirmed microscopically and demonstrate a key role for conventional PKC in NET formation.

PKC $\beta$ is Primarily Implicated in NET formation in Response to PMA and OAG

Gö 6976 is an inhibitor of both PKC $\alpha$ and $\beta$, thus, in order to separate the roles of these two isozymes, a specific PKC $\beta$ inhibitor (LY333531) was employed (Figure 4). LY333531 significantly inhibited NET formation by PMA at a concentration of $100 \mathrm{nM}(\mathrm{p}<0.05)$ and $1 \mu \mathrm{M}$ $(\mathrm{p}<0.01)$ (Figure 4A). In addition, 1-oleoyl-2-acetyl-snglycerol (OAG; a DAG analogue and activator of conventional $\mathrm{PKC}$ isoforms) stimulated NET formation in a manner similar to that of PMA (albeit at higher

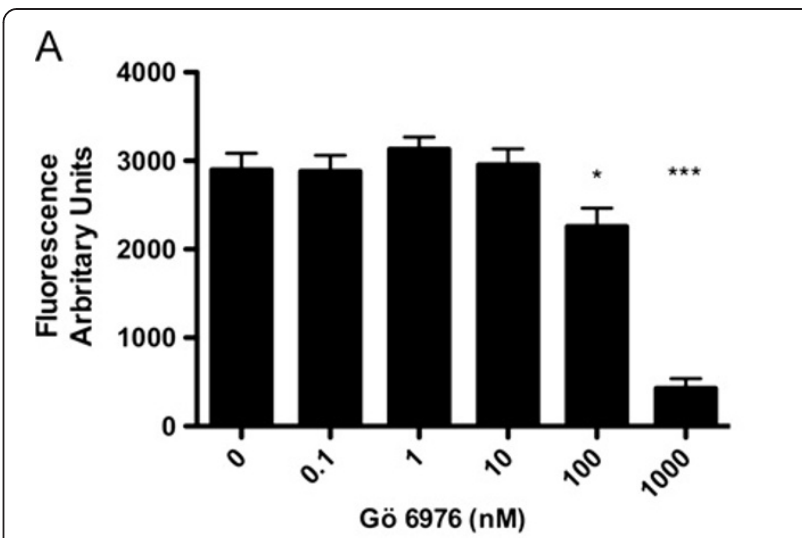

B
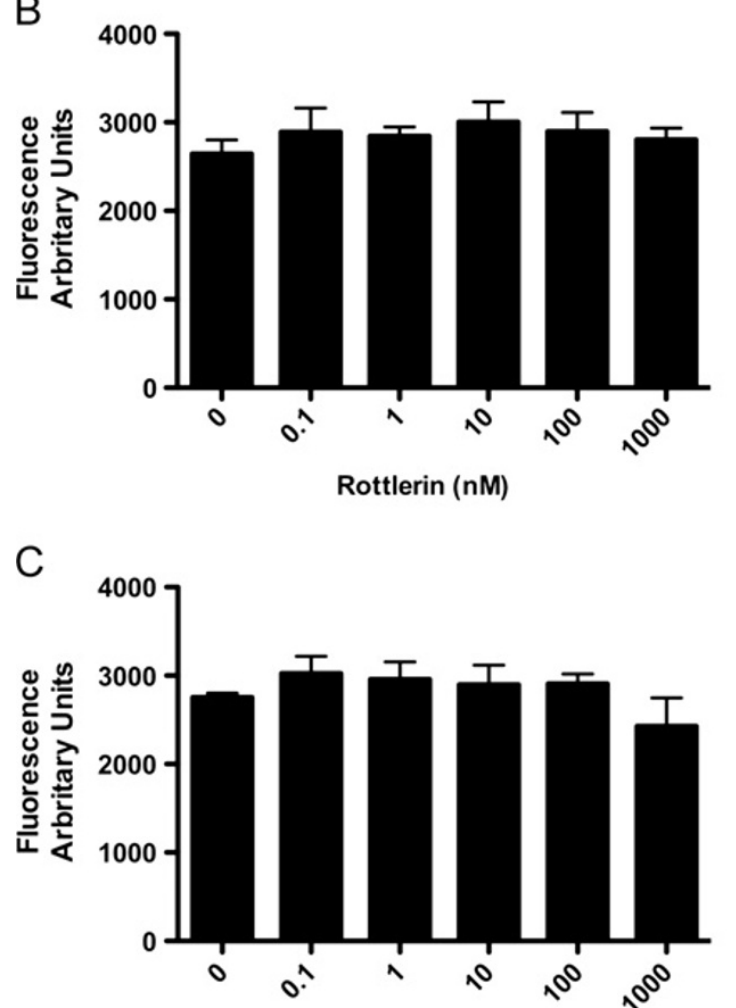

PKC $\zeta$ Pseudosubstrate Myristoyl Trifluoroacetate (nM)

Figure 3 Effect of isozyme specific PKC inhibitors on NET formation: Cells were plated as described and either pretreated with at increasing concentrations of Gö 6976 (conventional PKC inhibitor), Rottlerin (atypical PKC inhibitor), PKC psuedosubstrate (novel PKC inhibitor), or control media, before stimulation with PMA at $10 \mathrm{nM}$ for $4 \mathrm{~h}$. A) Pre-treatment with Gö 6976 significantly reduced NET formation at $100 \mathrm{nM}$ $(P<0.05)$ and $1 \mu \mathrm{M}(p<0.001)$. B) Pre-treatment with Rottlerin had no effect on NET formation. C) Pre-treatment with PKCद psuedosubstrate had no effect on NET formation. Data show mean $+/$ - SEM for $n=3$ independent experiments. ${ }^{*}$ indicates $p<0.05$, *** indicates $p<0.001$. 


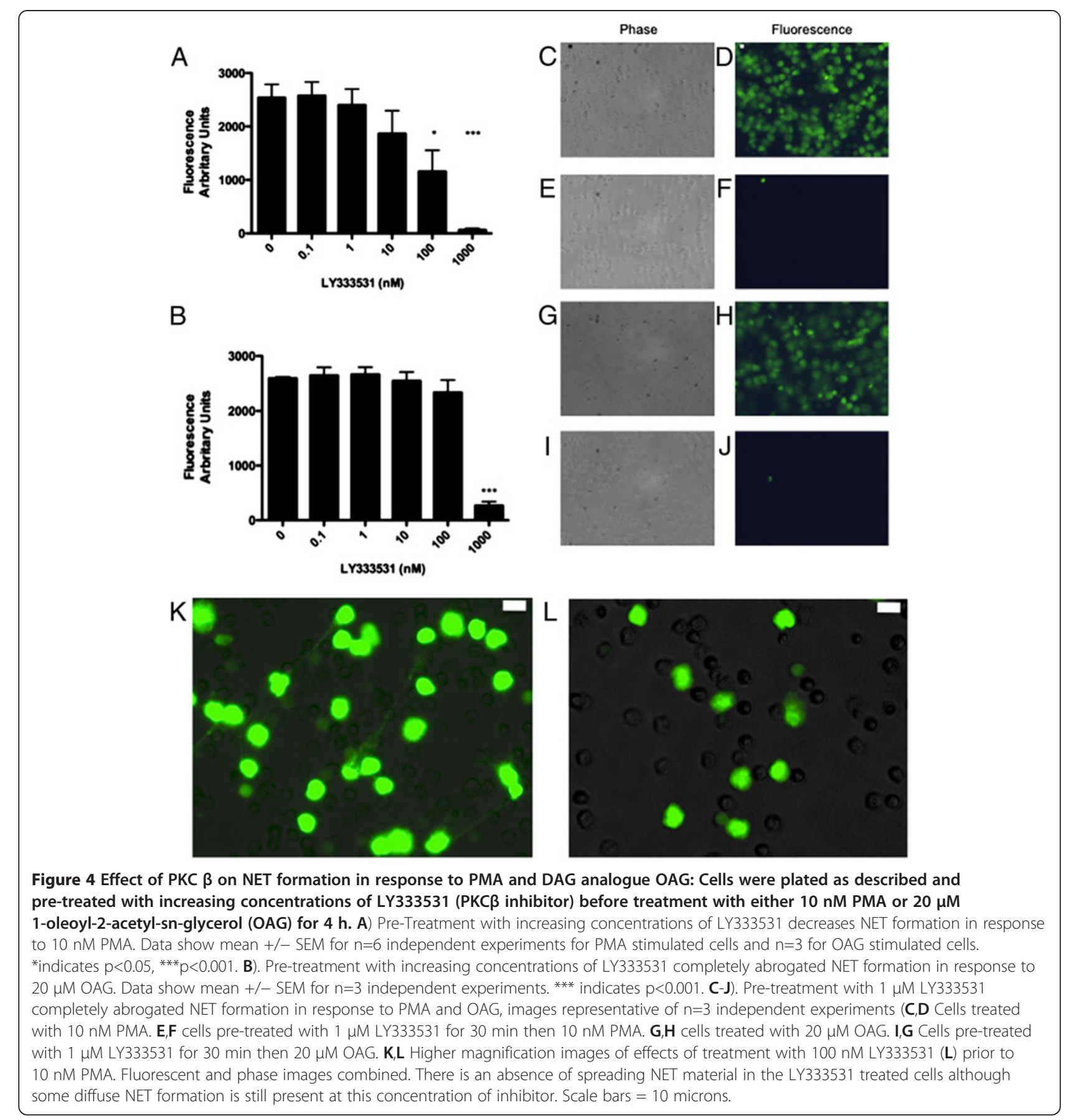

concentrations) and was also significantly inhibited by 1 MM LY333531 ( $<<0.01)$ (Figure 4B). These data were confirmed by microscopy and delineate a central role for PKC $\beta$ in PMA and OAG-induced NET formation (Figure 4C-J). Interestingly as well as knocking down total NET production LY333531 completely abrogated the presence of "spreading NETs" at the $100 \mathrm{~nm}$ concentration but some diffuse NET formation was still observed (Figure 4K,L).
PKC $\beta$ inhibition has downstream effects on oxidative burst

To elucidate the downstream effects of PKC $\beta$ inhibition we assessed the effects of LY333531 on oxidative burst as measured by DHR fluorescence on flow cytometry. LY333531 reduced NADPH oxidative burst at the same concentrations required to reduce NET formation, with a partial but significant knock down of activity at $100 \mathrm{nM}(\mathrm{p}<0.01)$ and a complete knockdown at $1 \mu \mathrm{M}$ 
$(\mathrm{p}<0.001)$ in comparison to the positive controls of DPI and Ro-31-8220 (Figure 5).

\section{Assessment of downstream effects of PKC $\beta$ inhibition with specific inhibitors}

ROS generation was assessed by dihydrorhodamine (DHR) fluorescence as described previously [13]. Neutrophils were resuspended in HBSS with cations and loaded with DHR (2 M; Invitrogen, Carlsbad, CA, USA) for $10 \mathrm{~min}$. Cells were then incubated with or without PKC $\beta$ inhibitor (at 10, 100 and $1000 \mathrm{nM}$ ) or the positive controls Ro-31-8220 or DPI at $1 \mu \mathrm{M}$ on a shaking heat block for $30 \mathrm{~min}$ before stimulation with PMA $10 \mathrm{nM}$ for a further $15 \mathrm{~min}$. DHR fluorescence was analyzed by flow cytometry (FL-1).

\section{Discussion}

The results clearly show that NET formation induced by PMA is PKC and NADPH oxidase dependent. NET formation was blocked by both Pan-PKC inhibition and conventional-PKC inhibition. Furthermore, a specific PKC $\beta$ inhibitor (LY333531) also blocked NET formation. LY333531 has high selectivity for PKC $\beta$ over other conventional isoforms (IC50 of around $5 \mathrm{nM}$ ) with a 60 fold selectivity for PKC $\beta$ over PKC $\alpha$ [15]. At higher concentrations specific inhibitors may have non-selective effects on other PKC isoforms. The IC50 of LY333531 for PKC $\alpha$ is around $300 \mathrm{nM}$, suggesting that the majority of the effect of this compound at the concentrations utilised in our study is via the inhibition of PKC $\beta$ and not PKC $\alpha$; this is evidenced by the significant reduction in NET formation with $100 \mathrm{nM}$ LY333531. The intracellular concentration of LY333531 within the neutrophil following incubation is unknown but it is unlikely to be fully absorbed and as such again we would suggest the effects are due to inhibition of PKC $\beta$. Previous work has demonstrated that $\mathrm{PKC} \beta$ accounts for $50 \%$ of the neutrophil response to PMA further underlining the likely predominant role of PKC $\beta$ in NET production [16].

Oxidative burst and the generation of reactive oxygen species including superoxide anions $\left(0_{2}^{-}\right)$and nitric oxide (NO) are fundamental responses of the neutrophil to inflammatory stimuli and pathogens. NET formation is dependent on NADPH oxidase activation and consequently on the generation of $\mathrm{O}_{2}^{-}$which can be blocked by DPI. DPI inhibits NADPH oxidase by binding to specific subunits in the enzyme complex and preventing electron flow and $0_{2}^{-}$production [17]. The main component of $\mathrm{NADPH}$ oxidase is the flavocytochrome b558, a dimer of p22phox and gp91phox, which is an active transporter of electrons across the membrane. Coupled to these are proteins p40phox, p47phox, p67phox and p21rac which are crucial to electron translocation [18]. These proteins assemble when activated to produce $0_{2}^{-}$which are then

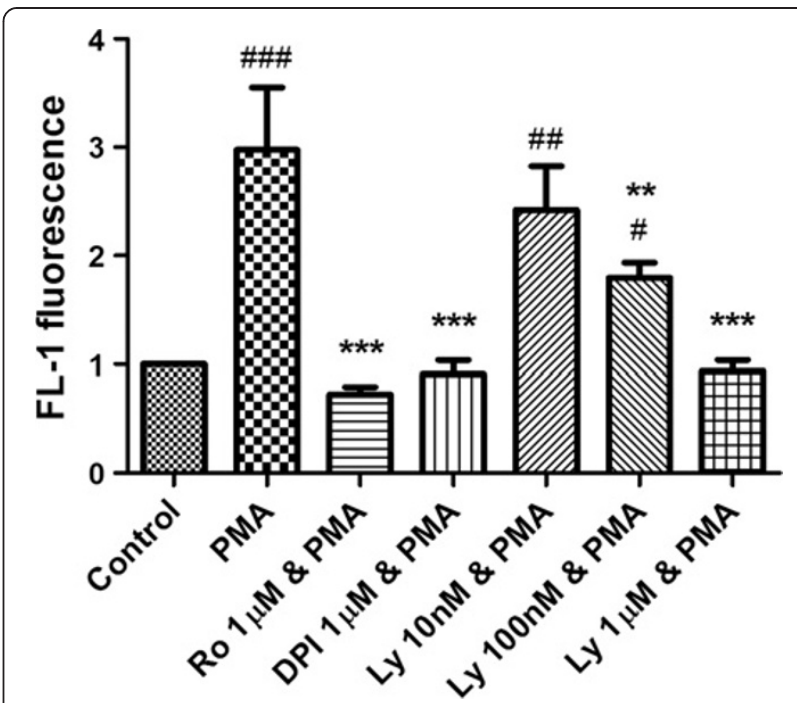

Figure 5 The downstream effect of PKC $\beta$ inhibition on oxidative burst. Cells were pretreated with LY333531 (Ly) at increasing concentrations and NADPH oxidase activity measured by DHR fluorescence on flow-cytometry. DPI and Ro-31-8220 (Ro) were used as positive controls. LY333531 reduced NADPH oxidase activity at both $100 \mathrm{nM}(\mathrm{p}<0.01)$ and $1 \mu \mathrm{M}(\mathrm{p}<0.001)$ consistent with the concentrations of inhibitor required to reduce NET formation. \# indicates $p<0.05$, \#\# indicates $p<0.01$, and \#\#\# indicates $p<0.001$ vs. untreated control. ${ }^{* *}$ indicates $p<0.01$ and ${ }^{* *}$ indicates $p<0.001$ vs. PMA treated cells.

spontaneously converted to $\mathrm{H}_{2} \mathrm{O}_{2}$. Interestingly, p47phox has to be phosphorylated to acquire a conformational rearrangement to expose the domains that are important for the NADPH oxidase function, and this phosphorylation is mediated by PKC [19]. This is consistent with our findings that PKC is involved in PMA induced NET formation and furthermore that $\mathrm{PKC} \beta$ is the isoform crucially involved. This is further underlined by the finding that oxidative burst is reduced by concentrations of LY333531 that reduce NET formation.

The beneficial anti-microbial effects of NET formation have been described in several studies [4,20-25]. Indeed, this is perhaps most pertinently displayed in restoration of NADPH oxidase function in chronic granulomatous disease by gene therapy leading to an increased resistance to fungal infection and clinical improvement secondary to the restoration of the ability to form NETs [22]. Several studies however have demonstrated a proinflammatory potential of NETs in a diverse range of diseases including systemic lupus erythematosus [26-28], cystic fibrosis $[1,29,30]$ and psoriasis [31]. Therefore the modulation of NET production may be a viable antiinflammatory target. Inhibition of PKC activity represents one such target as PKC inhibitors have been in development for many years as potential anti-cancer therapies, many of which are orally bioavailable [9]. Furthermore the relative redundancy in PKC function due 
to multiple isoforms may allow the targeting of specific PKCs in specific cell types at specific organ sites. PKC $\beta$ knock out in a murine model has been demonstrated to modulate ischemia reperfusion injury in vivo [32], however these mice may also be immunodeficient [33] and thus caution must be exercised in any strategy to specifically target PKC. Extracellular traps from both neutrophils and mast cells have been demonstrated in psoriatic skin lesions and from purified neutrophils from psoriasis patients in association with IL-17 and MPO, directly implicating extracellular traps in the pathogenesis of disease [31]. A previous study of a PKC inhibitor AEB071 with specificity for PKC $\alpha, \beta$, and $\theta$ in psoriasis demonstrated not only in-vitro effects on $\mathrm{T}$ cell proliferation and cytokine production but also a clinical improvement in psoriatic lesions in treated patients [34]. We may infer that some of this effect may be due to a direct effect of PKC inhibition on NET formation and thus inflammation in the skin lesions of these patients. Further studies will of course be required to support this hypothesis.

In summary, NET formation in response to PMA and DAG analogues is dependent on PKC activation. Furthermore, we demonstrate that conventional PKC and in particular $\mathrm{PKC} \beta$ is the predominant isoform responsible for NET formation under these conditions. Although NETs have been demonstrated to entrap and kill various microorganisms there is burgeoning evidence implicating a role for these structures in inflammatory disease and potential modulation of NET production (by PKC inhibition) may offer a novel anti-inflammatory strategy.

\section{Competing interests}

The authors declare that they have no competing interests.

\section{Authors' contributions}

RDG, CDL, AM, FL and KM carried out the experiments. RDG, CH, DJD and AGR designed the experiments and provided a critical review of methods. RDG drafted the manuscript. All authors read and approved the final manuscript.

\section{Funding}

RDG is a Wellcome Trust Fellow (093767). DD is an MRC Senior Research Fellow (G1002046). This work was also funded by the Wellcome Trust (WT094415; CL) and the MRC (G0601481; AGR and CH).

Received: 4 September 2012 Accepted: 22 February 2013

Published: 21 March 2013

\section{References}

1. Papayannopoulos V, Staab D, Zychlinsky A: Neutrophil elastase enhances sputum solubilization in cystic fibrosis patients receiving DNase therapy. PLoS One 2011, 6:e28526.

2. Nathan C: Neutrophils and immunity: challenges and opportunities. Nat Rev Immunol 2006, 6:173-182.

3. Brinkmann V, Zychlinsky A: Beneficial suicide: why neutrophils die to make NETs. Nat Rev Microbiol 2007, 5:577-582.

4. Brinkmann V, Reichard U, Goosmann C, Fauler B, Uhlemann Y, Weiss DS, Weinrauch Y, Zychlinsky A: Neutrophil extracellular traps kill bacteria. Science 2004, 303:1532-1535.

5. Fuchs TA, Abed U, Goosmann C, Hurwitz R, Schulze I, Wahn V, Weinrauch Y, Brinkmann V, Zychlinsky A: Novel cell death program leads to neutrophil extracellular traps. J Cell Biol 2007, 176:231-241.
6. Medina E: Neutrophil extracellular traps: a strategic tactic to defeat pathogens with potential consequences for the host. J Innate Immun 2009, 1:176-180.

7. Hakkim A, Fuchs TA, Martinez NE, Hess S, Prinz H, Zychlinsky A, Waldmann $\mathrm{H}$ : Activation of the Raf-MEK-ERK pathway is required for neutrophil extracellular trap formation. Nat Chem Biol 2011, 7:75-77.

8. Way KJ, Chou E, King GL: Identification of PKC-isoform-specific biological actions using pharmacological approaches. Trends Pharmacol Sci 2000, 21:181-187.

9. Roffey J, Rosse C, Linch M, Hibbert A, McDonald NQ, Parker PJ: Protein kinase C intervention: the state of play. Curr Opin Cell Biol 2009, 21:268-279.

10. Balasubramanian N, Advani SH, Zingde SM: Protein kinase C isoforms in normal and leukemic neutrophils: altered levels in leukemic neutrophils and changes during myeloid maturation in chronic myeloid leukemia. Leuk Res 2002, 26:67-81.

11. Haslett C, Guthrie LA, Kopaniak MM, Johnston RB Jr, Henson PM: Modulation of multiple neutrophil functions by preparative methods or trace concentrations of bacterial lipopolysaccharide. Am J Pathol 1985, 119:101-110.

12. Rossi AG, Sawatzky DA, Walker A, Ward C, Sheldrake TA, Riley NA, Caldicott A, Martinez-Losa M, Walker TR, Duffin R, et al: Cyclin-dependent kinase inhibitors enhance the resolution of inflammation by promoting inflammatory cell apoptosis. Nat Med 2006, 12:1056-1064.

13. Lucas CD, Allen KC, Dorward DA, Hoodless LJ, Melrose LA, Marwick JA, Tucker CS, Haslett C, Duffin R, Rossi AG: Flavones induce neutrophil apoptosis by down-regulation of $\mathrm{Mcl}-1$ via a proteasomal-dependent pathway. FASEB J 2013, 27(3):1084-1094.

14. Metzler KD, Fuchs TA, Nauseef WM, Reumaux D, Roesler J, Schulze I, Wahn $\checkmark$, Papayannopoulos $V$, Zychlinsky A: Myeloperoxidase is required for neutrophil extracellular trap formation: implications for innate immunity. Blood 2010, 117:953-959.

15. Jirousek MR, Gillig JR, Gonzalez CM, Heath WF, McDonald JH 3rd, Neel DA, Rito CJ, Singh U, Stramm LE, Melikian-Badalian A, et al: (S)-13-[(dimethylamino) methyl]-10,11,14,15-tetrahydro-4,9:16, 21-dimetheno-1H, 13H-dibenzo[e, k] pyrrolo[3,4-h][1,4,13]oxadiazacyclohexadecene-1,3(2H)-d ione (LY333531) and related analogues: isozyme selective inhibitors of protein kinase $\mathrm{C}$ beta. J Med Chem 1996, 39:2664-2671.

16. Dekker LV, Leitges M, Altschuler G, Mistry N, McDermott A, Roes J, Segal AW: Protein kinase C-beta contributes to NADPH oxidase activation in neutrophils. Biochem J 2000, 347(Pt 1):285-289.

17. Doussiere J, Vignais PV: Diphenylene iodonium as an inhibitor of the NADPH oxidase complex of bovine neutrophils. Factors controlling the inhibitory potency of diphenylene iodonium in a cell-free system of oxidase activation. Eur J Biochem 1992, 208:61-71.

18. Segal AW: How neutrophils kill microbes. Annu Rev Immunol 2005, 23:197-223.

19. Babior BM, Lambeth JD, Nauseef W: The neutrophil NADPH oxidase. Arch Biochem Biophys 2002, 397:342-344.

20. Yost CC, Cody MJ, Harris ES, Thornton NL, Mclnturff AM, Martinez ML, Chandler NB, Rodesch CK, Albertine KH, Petti CA, et al: Impaired neutrophil extracellular trap (NET) formation: a novel innate immune deficiency of human neonates. Blood 2009, 113:6419-6427.

21. Urban CF, Reichard U, Brinkmann V, Zychlinsky A: Neutrophil extracellular traps capture and kill Candida albicans yeast and hyphal forms. Cell Microbiol 2006, 8:668-676.

22. Bianchi M, Hakkim A, Brinkmann V, Siler U, Seger RA, Zychlinsky A, Reichenbach J: Restoration of NET formation by gene therapy in CGD controls aspergillosis. Blood 2009, 114:2619-2622.

23. Ermert D, Urban CF, Laube B, Goosmann C, Zychlinsky A, Brinkmann V: Mouse neutrophil extracellular traps in microbial infections. J Innate Immun 2009, 1:181-193.

24. Papayannopoulos V, Zychlinsky A: NETs: a new strategy for using old weapons. Trends Immunol 2009, 30:513-521.

25. Urban CF, Ermert D, Schmid M, Abu-Abed U, Goosmann C, Nacken W, Brinkmann V, Jungblut PR, Zychlinsky A: Neutrophil extracellular traps contain calprotectin, a cytosolic protein complex involved in host defense against Candida albicans. PLoS Pathog 2009, 5:e1000639.

26. Lande R, Ganguly D, Facchinetti V, Frasca L, Conrad C, Gregorio J, Meller S, Chamilos G, Sebasigari R, Riccieri V, et al: Neutrophils activate plasmacytoid dendritic cells by releasing self-DNA-peptide complexes in systemic lupus erythematosus. Sci Transl Med 2011, 3:73ra19. 
27. Leffler J, Martin M, Gullstrand B, Tyden H, Lood C, Truedsson L, Bengtsson AA, Blom AM: Neutrophil extracellular traps that are not degraded in systemic lupus erythematosus activate complement exacerbating the disease. J Immunol 2012, 188(7):3522-3531.

28. Garcia-Romo GS, Caielli S, Vega B, Connolly J, Allantaz F, Xu Z, Punaro M, Baisch J, Guiducci C, Coffman RL, et al: Netting neutrophils are major inducers of type I IFN production in pediatric systemic lupus erythematosus. Sci Transl Med 2011, 3:73ra20.

29. Manzenreiter R, Kienberger F, Marcos V, Schilcher K, Krautgartner WD, Obermayer A, Huml M, Stoiber W, Hector A, Griese M, et al: Ultrastructural characterization of cystic fibrosis sputum using atomic force and scanning electron microscopy. J Cyst Fibros 2012, 11(2):84-92.

30. Marcos V, Zhou Z, Yildirim AO, Bohla A, Hector A, Vitkov L, Wiedenbauer EM, Krautgartner WD, Stoiber W, Belohradsky BH, et al: CXCR2 mediates NADPH oxidase-independent neutrophil extracellular trap formation in cystic fibrosis airway inflammation. Nat Med 2010, 16:1018-1023.

31. Lin AM, Rubin CJ, Khandpur R, Wang JY, Riblett M, Yalavarthi S, Villanueva EC, Shah P, Kaplan MJ, Bruce AT: Mast cells and neutrophils release IL-17 through extracellular trap formation in psoriasis. J Immunol 2011, 187:490-500.

32. Kong L, Andrassy M, Chang JS, Huang C, Asai T, Szabolcs MJ, Homma S, Liu $R$, Zou YS, Leitges M, et al: PKCbeta modulates ischemia-reperfusion injury in the heart. Am J Physiol Heart Circ Physiol 2008, 294:H1862-H1870.

33. Leitges M, Schmedt C, Guinamard R, Davoust J, Schaal S, Stabel S, Tarakhovsky A: Immunodeficiency in protein kinase cbeta-deficient mice. Science 1996, 273:788-791.

34. Skvara H, Dawid M, Kleyn E, Wolff B, Meingassner JG, Knight H, Dumortier T, Kopp T, Fallahi N, Stary G, et al: The PKC inhibitor AEB071 may be a therapeutic option for psoriasis. J Clin Invest 2008, 118:3151-3159.

doi:10.1186/1476-9255-10-12

Cite this article as: Gray et al: Activation of conventional protein kinase $C$ (PKC) is critical in the generation of human neutrophil extracellular traps. Journal of Inflammation 2013 10:12.

\section{Submit your next manuscript to BioMed Central and take full advantage of:}

- Convenient online submission

- Thorough peer review

- No space constraints or color figure charges

- Immediate publication on acceptance

- Inclusion in PubMed, CAS, Scopus and Google Scholar

- Research which is freely available for redistribution 